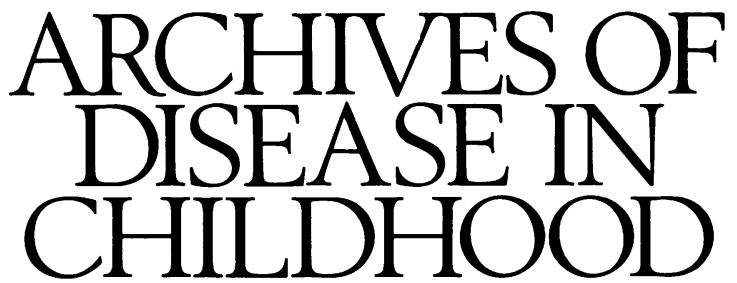

The fournal of the British Paediatric Association

\title{
Annotations
}

\section{Transcutaneous carbon dioxide monitoring}

The skin of a preterm baby has a thin epidermis and is poorly keratinised, which facilitates the measurement of oxygen, carbon dioxide, and bilirubin, and provides an absorptive surface for drugs and oxygen. ${ }^{12}$ The idea of transcutaneous monitoring developed after the permeability of skin was described in $1851,{ }^{3}$ and was first used successfully in $1972 .{ }^{4}$ Miniature devices for measuring blood gas tension have now become usefully established in many neonatal units. The continuous availability of measurements of oxygen tension has alerted those who work in nurseries to the short term fluctuations that can occur during apparently innocuous procedures such as feeding, noise, and nappy changes. ${ }^{5}$ Maintenance of a constant carbon dioxide tension is equally as important as a stable oxygen tension in babies with respiratory failure: why, then, has transcutaneous carbon dioxide monitoring 'never come out of the oven'? (P Rolfe, 3rd International Congress of Fetal and Neonatal Physiological Measurements, Sweden, 1988).

\section{Need for carbon dioxide monitoring}

Frequent analyses of both arterial oxygen and carbon dioxide are essential to assess the adequacy of support in babies with respiratory failure. The usual diagnosis will be that of the respiratory distress syndrome, but the group includes babies ventilated for meconium aspiration, pulmonary hypoplasia, pneumonia, myopathy, and birth asphyxia. Hypercarbia is a potent vasodilator and has been implicated in the aetiology of periventricular haemorrhage, ${ }^{6}$ and hypocarbia with its vasoconstrictor effect may reduce cerebral blood flow and contribute to ischaemic lesions of the brain. ${ }^{7}$ Early detection of a rising carbon dioxide tension sometimes provides warning of blockage of an endotracheal tube at a stage when suction is sufficient to clear the secretions, obviating the need for the endotracheal tube to be changed. A pneumothorax can be diagnosed before the development of tension results in serious cardiovascular consequences. ${ }^{8}$ After extubation knowledge of accumulating carbon dioxide can be particularly helpful in identifying babies who are making inadequate respiratory effort before they develop acidosis and bradycardia, and the same is true after operation and during transport.

During the treatment of persistent pulmonary hypertension it may be necessary to achieve a carbon dioxide tension as low as $2 \mathrm{kPa}$ before reducing the pulmonary arterial pressure. ${ }^{9}$ Hyperventilation and maintenance of hypocarbia is also indicated in some cases of birth asphyxia. ${ }^{10}$ There seems little doubt, therefore, that continuous monitoring of carbon dioxide tension can assist clinical care.

\section{Technique of measurement}

The most commonly used type of electrode is based on the $\mathrm{pH}$ determination of a thin film of electrolyte separated from the skin by a hydrophobic membrane permeable to carbon dioxide but not to hydrogen ions. When carbon dioxide diffuses through the membrane there is a change in the $\mathrm{pH}$ of the electrolyte, as carbon dioxide reacts with water to form hydrogen and bicarbonate ions. Determination of the $\mathrm{pH}$ of the solution thus gives an indirect measure of carbon dioxide, the potential difference between the $\mathrm{pH}$ electrode and a metal reference electrode being proportional to the logarithm of the partial pressure of carbon dioxide. ${ }^{11}$ This method of measurement does not use a polarographic electrode and so does not consume carbon dioxide. During transcutaneous measurement of oxygen using a polarographic electrode a cathode and anode have a polarising voltage passed through them, which reduces oxygen and results in the formation of hydroxyl ions and the production of a current proportional to the amount of oxygen present. ${ }^{12}$

By combining the reference electrodes and providing a cathode for oxygen and a glass $\mathrm{pH}$ electrode, a combined sensor can be made. ${ }^{13}$ For each oxygen molecule consumed in this type of electrode four electrons are produced and hence four hydroxyl pairs. These will react with any carbon dioxide present to form bicarbonate, causing the partial pressure of carbon dioxide in the solution to reduce over time: Severinghaus has described an elegant solution to the design of combined oxygen/carbon dioxide sensors in which the hydroxyl produced at the cathode is consumed at the anode. ${ }^{14}$

\section{Accuracy of measurement}

For transcutaneous measurements to reflect arterial blood gas tensions it is necessary to warm the skin, 'arterialising' the capillaries. In combined electrodes the operating temperature has to be $44^{\circ} \mathrm{C}$ to promote skin hyperperfusion and to obtain a correlation between arterial and skin oxygen tension. Heating the electrode also improves the response time. Carbon dioxide is more readily diffusable than oxygen, and carbon dioxide electrodes can be operated satisfactorily at lower temperatures than oxygen sensors. A better correlation with arterial blood gas tension is usually obtained at higher operating temperatures, ${ }^{15}$ although Wimberley $e t$ al found an increasing difference with increasing operating temperature. ${ }^{16}$

In spite of arterialisation of the capillaries, the transcutaneous carbon dioxide measurement is always greater than the corresponding arterial measurement; the overread- 
ing results partly from local tissue production of carbon dioxide (amounting to about $0.5 \mathrm{kPa}$ ) ${ }^{17}$ and partly from the heating coefficient of blood. The readings are approximately $1 \cdot 27$ times or $27 \%$ higher. A correction factor of 0.77 can be applied to the value obtained from a transcutaneous monitor to estimate the arterial partial pressure.

A transcutaneous carbon dioxide electrode needs calibrating against a known concentration of carbon dioxide every time it is removed from a baby, which needs to be at least every four hours to protect the skin and is often more frequent. After calibration a period of stabilisation of about 10 minutes is required before readings become stable. The time constant (63\% response time) for changes in carbon dioxide tension after this is about 60 seconds. ${ }^{13} 18$ Several careful studies have examined the accuracy of transcutaneous monitors in a clinical setting. Martin et al studied 60 newborn infants with a mean birthweight $2200 \mathrm{~g} .{ }^{19}$ Forty eight had respiratory distress syndrome, and none was hypotensive. Transcutaneous carbon dioxide tension was accurate over the hypocarbic range, but overestimated by a mean (SD) of $0.66(0.53) \mathrm{kPa}$ in the normal range and by 1.2 $(0.8) \mathrm{kPa}$ in the hypercarbic range. The values deviated from the line of identity even after the type of correction described above, with a slope that increased as the amount of carbon dioxide increased. The authors thought that there may have been an imbalance between carbon dioxide production and removal in hypercarbia, perhaps as a result of local shunting. A Danish study of 64 newborns with respiratory distress confirmed the overestimation shown by others, with a correction factor of 0.7 resulting in correct grouping of $82 \%$ of the values. ${ }^{19}$ Sensitivity and specificity were between $72 \%$ and $88 \%$ with a coefficient of variation of $5 \cdot 3 \%$. Overall, the correlation between arterial and transcutaneous measurements was good, with $r=0.9$ to 0.95 at different electrode temperatures. Large drifts were experienced, however, with 543 check calibrations showing a mean drift of $+2 \cdot 6 \%$, SD $6 \%$, and range $33 \%$. Similar problems were experienced by Kost et $a l^{20}$ who found a drift larger than $0.4 \mathrm{kPa} /$ hour in $10 \%$ of 500 monitoring sessions, and at University College Hospital, ${ }^{13}$ where the calibration against $10 \%$ carbon dioxide drifted down at $0.3 \mathrm{kPa} /$ hour. Lee et al evaluated two combined sensors in older children and found them to be generally accurate, although the oxygen electrode had a reduced performance when compared with a single sensor. ${ }^{21}$ Drift was small for the carbon dioxide electrode, at $-0.2 \mathrm{kPa}$ in four hours. The reason for the drift is not known, but because it is larger in vivo than when an electrode is left in calibration gas, one explanation has been that it is due to pressure sensitivity of the electrode.

\section{Limitations of the method}

In the appropriate setting, surface carbon dioxide tension can be used to predict arterial carbon dioxide tension with a reliability similar to that of transcutaneous oxygen monitoring. The difficulty of remembering to apply a correction factor can easily be overcome by adjusting the sensor to underestimate the calibration gas-for example, to read $7 \mathrm{kPa}$ in $10 \%$ carbon dioxide. The method is free from serious side effects, although skin craters have been described. $^{22}$ The cost of commercial equipment ranges from $£ 2000$ to $£ 6000$, the electrodes are fragile and expensive, and the systems require special calibration gas. The result is not reliable in shocked babies, ${ }^{23}$ and although there have been no adverse effects shown from hypothermia, acidosis, sclerema, or anaemia, all these factors are known to affect transcutaneous oxygen estimation and the presence of any of them would make most clinicians unwilling to rely on transcutaneous monitoring. ${ }^{24}$ increasing thickness of the epidermal layer with increasing postnatal age makes the method inaccurate in bronchopulmonary dysplasia. ${ }^{25}$

\section{Conclusion}

In spite of the attractions of continuous carbon dioxide monitoring, and the availability of combined oxygen and carbon dioxide sensors, the method has yet to become established in neonatal intensive care. Used carefully there is no doubt that it is capable of providing an accurate result for a clinically important variable. The limitations are not only cost, but also the fragility of the equipment, and the need for repeated calibration against a gas other than air (followed by the considerable time taken for stabilisation). Babies with variable carbon dioxide tensions are often those who are hypotensive, and who require repeated investigations necessitating resiting of electrodes. This results in readings that are unreliable and often unavailable at a crucial moment, which has perhaps led to disillusion. To continue the analogy from the introduction, perhaps the next decade will enable continuous non-invasive carbon dioxide monitoring to be 'fully baked'.

Department of Paediatrics,

J M RENNIE

Level 8, Addenbrooke's Hospital,

Hills Road, Cambridge CB2 $2 Q Q$

1 Harpin VA, Rutter N. Barrier properties of the newborn infant's skin 7 Pediatr 1983;102:419-24.

2 Cartlidge PHT, Rutter N. Percutaneous oxygen delivery to the preterm infant. Lancet 1988;i:315-7.

3 Gerlach P. Uber das Hautathmen. Archives of Anatomy and Physiology 1851: 431-79.

4 Huch R, Lubbers DW, Huch A. Quantitative continuous measurement of partial oxygen pressure on the skin of adults and newborn babies. Pflugers Arch 1972;337:185-7.

5 Long JG, Philip AGS, Lucey JF. Excessive handling as a cause of hypoxaemia. Pediatrics 1980;65:203-7.

6 Cooke RWI. Factors associated with periventricular haemorrhage in very low birthweight infants. Arch Dis Child 1981; 56:425-31.

7 Griesen G, Munck H, Lou H. Severe hypocarbia in preterm infants and neurolodevelopmental deficit. Acta Paediatr Scand 1987;76:401-4.

8 Lipscomb AP, Thorburn RJ, Reynolds EOR, et al. Pneumothorax and cerebral haemorrhage in preterm infants. Lancet 1981;i:414-16.

9 Fox WW, Duara S. Persistent pulmonary hypertension in the neonate. F Pediatr 1983;103:505-15.

10 Svenningsen NW, Blennow G, Lindroth $M$, et al. Brain-orientated intensive care treatment in severe neonatal asphyxia. Arch Dis Child 1982;57:176-83.

11 Eberhard P. Skin sensor for continuous monitoring of PCO2. Measuring principle. In: Rolfe P, ed. Fetal and neonatal physiological measurements. London: Pitman Medical, 1980:413-7.

12 Clark LC. Monitor and control of blood and tissue oxygen tension. Transactions of the American Society of Artificial Internal Organs 1956;2:41-2.

3 Whitehead MD, Halsall D, Pollitzer MJ. Trancutaneous estimation of arteria $\mathrm{PO} 2$ and $\mathrm{PCO} 2$ in newborn infants with a single elecrochemical sensor. Lancet 1980; i:1111-4.

14 Severinghaus JW. A combined transcutaneous PO2-PCO2 electrode with electrochemical HCO3- stabilisation. 7 Appl Physiol 1981;51:1027-32.

15 Herrell N, Martin RJ, Pultusker M, Fanaroff A. Optimal temperature for the measurement of tenscutaneous carbon dioxide tension in the neonate. f Pediatr 1980;97:114-7.

16 Wimberley PD, Frederiksen PS, Witt-Hansen J et al. Evaluation of a transcutaneous oxygen and carbon dioxide monitor. Acta Paediatr Scand 1985; cutaneous

17 Hansen TN, Tooley WH. Skin surface carbon dioxide tension in sick infants. Pediatrics 1979;64:942-5.

8 Peabody JL, Emery JR. Noninvasive monitoring of blood gases in the newborn. Clin Perinatol 1985;12:147-60.

19 Martin RJ, Beoglos A, Miller MJ, et al. Increasing arterial carbon dioxide tension: influence on transcutaneous carbon dioxide tension measurements. Pediatrics 1988;81:684-7.

20 Kost GJ, Chow JL, Kenny MA. Monitoring of transcutaneous carbon dioxide tension. Am Y Clin Pathol 1983;80:832-8.

21 Lee HK, Broadhurst E, Helms P. Evaluation of two combined oxygen and carbon dioxide transcutaneous sensors. Arch Dis Child 1989;64:279-82.

22 Golden SM. Skin craters - a complication of transcutaneous oxygen monitoring. Pediatrics 1981;67:514-6.

23 Brunstler I, Enders A, Versmold HT. Skin surface PCO2 monitoring in newborn infants in shock: effect of hypotension and electrode temperature. J Pediatr 1982;100:454-7.

24 Cassady G. Transcutaneous monitoring. F Pediatr 1983;103:837-46.

25 Rome ES, Stork EK, Carlo WA, Martin RJ. Limitations of transcutaneous $\mathrm{PO} 2$ and $\mathrm{PCO} 2$ monitoring in infants with bronchopulmonary dysplasia. Pediatrics 1984;74:217-20. 